\title{
Influence of certain tooth characteristics on the esthetic evaluation of a smile
}

\author{
Andréa Fonseca Jardim da Motta', José Nelson Mucha², Margareth Maria Gomes de Souza ${ }^{3}$
}

Objective: To assess the influence of certain dental characteristics on the perception of smile esthetics by undergraduate dentistry students.

Methods: Ten digital photographs of a woman's smile were modified using Adobe Photoshop software. The following changes were performed: stain removal; incisal edge straightening; gingival leveling; closure of black triangles. A group of 60 undergraduate dental students evaluated the original photograph and the altered images using a visual analog scale to evaluate smile esthetics. Intraexaminer agreement was checked for 30 examiners using the Student $t$ test; for casual error, the Dahlberg formula was used. Data were described as means and standard deviations, and reported in tables.

Results: There were no statistically significant differences between the first and second scores assigned by examiners ( $>0.05)$ in any of the comparisons made. The results of systematic error for the method indicated that the measures obtained were reliable. ANOVA was used to test equality of means, and the level of significance was set at 5\%. Equality of variances was evaluated using Levene's test, and results revealed that variances were equal. Multiple comparisons using the Tukey's test revealed statistical significance at a 5\%level for the presence of black triangular space. No significant values were found for other comparisons.

Conclusions: Some dental characteristics were perceived by undergraduate students, and the black triangular space was classified as the most unfavorable characteristic.

Keywords: Smile. Dental esthetics. Perception.

» Patients displayed in this article previously approved the use of their facial and intraoral photographs.

${ }^{1}$ Assistant Professor, Undergraduate and Graduate Program in Orthodontics, Federal Fluminense University (UFF), Niterói, Brazil.

${ }^{2}$ Head Professor, Orthodontics, UFF. Professor, Specialization Course in Orthodontics, UFF.

${ }^{3}$ Head Professor of Orthodontics, Undergraduate and Graduate Program in Orthodontics, School of Dentistry, Federal University of Rio de Janeiro (UFRJ), Rio de Janeiro, Brazil.
How to cite this article: Motta AFJ, Mucha JN, Souza MMG. Influence of certain tooth characteristics on the esthetic evaluation of a smile. Dental Press J Orthod. 2012 May-June;17(3):25.el-7.

Submitted: January 21, 2009 - Revised and accepted: February 18, 2010

» The authors report no commercial, proprietary, or financial interest in the products or companies described in this article.

Contact address: Andréa Fonseca Jardim da Motta Orthodontics department, School of Dentistry, Federal Fluminense University (UFF) Rua Mário Santos Braga, 30, $2^{\circ}$ andar, sala 214 - Niterói/RJ, Brazil

Zip code: 24.020-140 - E-mail: andreamotta@id.uff.br 


\section{INTRODUCTION}

Facial beauty, as well as smile esthetics, affects the well-being of many patients and draws the attention of dentists to the fact that constant updating in this field is necessary. The term esthetics comes from the Greek word "aisthesis", which means perception or sensation and for being such a subjective concept due to differences in taste and opinion, it creates disagreement both between dentists and patients. ${ }^{8}$

Current perspectives of dental practice and research demand that dentists get closer to their patients' expectations when the improvement of facial and smile esthetics is the treatment goal. The main aspiration of patients is to be seen as beautiful, or, at least, normal by themselves and by society, which can be achieved by eliminating unpleasant characteristics of their smile and face.

Some dental characteristics are more easily perceptible in a smile than others and may cause greater or lesser interference with smile esthetics' results .

According to some authors, an anatomically correct interdental papilla and healthy gingiva in harmony with natural dentition are important esthetic aspects in determining diagnosis and treatment. ${ }^{6,12,14}$ Changes in gingival contour, color and height, as well as the presence of black triangles between central incisors associated with a missing interdental papilla, may depreciate the esthetic quality of smile. ${ }^{6,79,15} \mathrm{~A}$ missing papilla may also result in phonetic problems and food impaction. ${ }^{15}$ Similarly, the presence of stains on teeth may compromise smile esthetics. Another characteristic usually analyzed during the evaluation of smile esthetics is the incisal edge contour.

Several authors ${ }^{3,5,13}$ have evaluated the esthetic perception of different types of malocclusion, but few studies in the literature investigated the effect of dental peculiarities on the perception of smile esthetics..$^{10}$ In addition, study findings are often contradictory about the relevance of the perception of certain characteristics. ${ }^{5,10}$ These contradictions may result from differences in examiners ' level of training to assess defects or, still, the under- or overestimation of certain characteristics by examiners with different backgrounds.

The aim of this study is to investigate the effect of certain dental characteristics on the evaluation of smile esthetics by undergraduate Dentistry students in the senior year.

\section{MATERIAL AND METHODS}

A digital photograph of the smile of a woman with well-aligned teeth was modified using Adobe Photoshop 2.0 (Adobe Systems Inc, San Jose, CA) to alter some predetermined characteristics.

The changes made in the original photograph were:

a. A yellowed stain was removed from the mesiobuccal surface of tooth \# 26.

b. The incisal edge of tooth \# 22 was straightened.

c. The gingival margin height of tooth \#12 was leveled.

d. The black triangular space between teeth \# 11 and \#21 was filled.

Changes were performed so that two sets of photographs were obtained for the evaluation of each characteristics perception on the assessment of smile esthetics using two different manners.

For the first evaluation, called characteristic exclusion, the original photograph was maintained and four other photographs were produced based on the original, each with only one characteristic altered. In the second evaluation, called characteristic inclusion , the process was reversed. The original photograph was fully corrected excluding all the characteristics under analysis, and other four photographs were produced based on the original, each displaying only one characteristic (Figs 1 and 2).

The five images in each set (Figs 1 and 2) were distributed randomly, numbered and organized in two multimedia presentations using PowerPoint 2007(Microsoft Office 2007): one with the inclusion of the characteristics, and the other, with their exclusion.

Images were projected using a Sony VLP-CS7 projector, 1800 ANSI lumens, SVGA (800x600), and a $3 \times 2 \mathrm{~m}$ screen. The examiners faced this screen at a distance of 3 to 6 meters in a room with reduced lighting to avoid compromising image visualization, but still allow examiners to make notes on the proper forms.

To assess the effect of dental characteristics on the perception of smile esthetics, the scores assigned by 60 students ( 22 male, 38 female, mean age $=22$ years 4 months) of the Orthodontics Course of the Undergraduate Dentistry Course of Federal Fluminense University (UFF) were processed.

Before the images were displayed for evaluation (Figs 1 and 2), students watched a multimedia presen- 

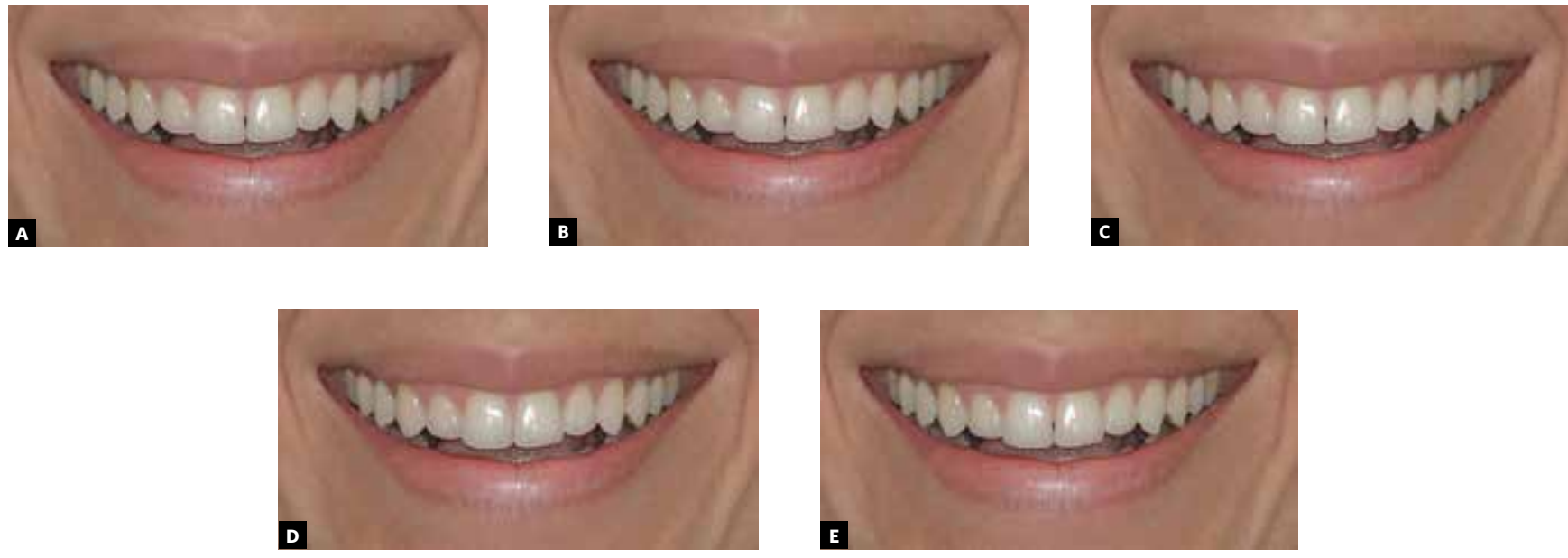

Figure 1 - A) Removal of yellowed stain from mesiobuccal surface of tooth \# 26; B) Straightening of tooth \# 22 incisal edge; C) Leveling of tooth \#12 gingival margin height; D) Filling of black triangular space between teeth \# 11 and 21; and $\mathbf{E}$ ) reference photograph with all characteristics uncorrected.
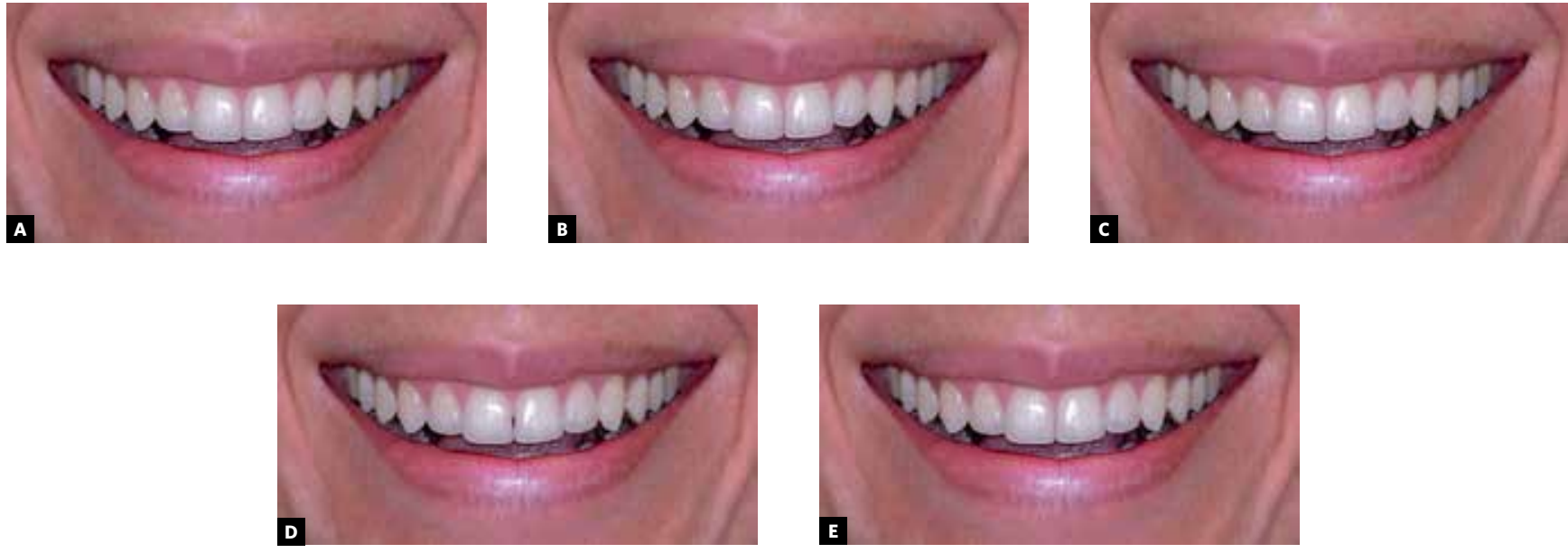

Figure 2 - A) Presence of yellowed stain on mesiobuccal surface of tooth \# 26; B) Triangular and asymmetric incisal edge of tooth \#22; C) Asymmetric gingival contour between teeth \# 12 and 22; D) Black triangular space between teeth \# 11 and 21; and E) reference photograph with all characteristics corrected.

tation of several characteristics that may affect smile esthetics to ensure the same level of knowledge. Each photograph was then projected for 20 seconds, with no second chances allowed. Each examiner received a form with 10 visual analog scales (VAS) numbered from 0 to 100, one for each photo. The lowest score should be assigned to the least attractive smile, and the highest, to the most attractive.

After the students' assessment by grading the smiles aesthetics using the scales, data were organized by only one operator using a digital caliper (Starret Indústria e Comércio Ltda., Itu, São Paulo, Brazil; serial number 001296) calibrated to the VAS. The cali- per was placed at point zero and extended to the mark made by the examiner. Tables were arranged to obtain central tendency measures.

To check intraexaminer agreement in the subjective evaluation of smile esthetics on the projected photographs, 30 students were randomly selected and asked to repeat the evaluation one week later (T1 and T2). In order to analyze systematic intraexaminer error, the Student $t$ test for paired samples was used. To determine casual error, the Dahlberg formula was used. ${ }^{2}$

Data were described as mean and standard deviation and reported in tables. This same procedure was 
followed for the two evaluation forms: exclusion and inclusion of characteristics.

Analysis of variance (ANOVA) was used to test the equality of means in the groups of measures, for both the first and the second evaluation. Multiple comparisons were proceeded by the Tukey test, and the Levene test was used to test equality of variance. The level of significance was set at $5 \%$ for all tests.

\section{RESULTS}

The results for systematic error using the $t$ test for paired samples and for the casual error measured by Dahlberg's formula are shown in Tables 1 and 2. There was no difference between the first (Tl) and second (T2) scores assigned by examiners at a level of significance of $5 \%(\mathrm{p}>0.05)$ in any of the comparisons made.
Results for method error revealed reliable measures due to great reproducibility potential.

Means and standard deviations for each characteristic under analysis for both evaluations are shown in Table 3.

Figure 3 shows mean values for the assessed characteristics in the two situations: with exclusion and inclusion of characteristics.

The results of ANOVA, used to test the equality of means in the groups of measures, were significant at the level of $5 \%$, both for the first and second evaluations. Equality of variances, evaluated using the Levene's test, revealed that variances were equal. After multiple comparisons using the Tukey test, the presence of a black triangular space was statistically significant at a level of $5 \%$ when compared with the

Table 1- Mean and standard deviation (SD) values at T1 and T2, t test for paired samples and Dahlberg's formula for assessment of systematic error and casual error for measurements in the first evaluation.

\begin{tabular}{|c|c|c|c|c|c|c|c|}
\hline \multirow[t]{2}{*}{$\begin{array}{c}\text { Characteristics } \\
\text { (exclusion) }\end{array}$} & \multicolumn{2}{|c|}{$\mathbf{T}_{1}$} & \multicolumn{2}{|c|}{$\mathbf{T}_{2}$} & \multirow[t]{2}{*}{$\mathbf{t}$} & \multirow[t]{2}{*}{$\mathbf{p}$} & \multirow[t]{2}{*}{ Dahlberg } \\
\hline & Mean & SD & Mean & SD & & & \\
\hline yellowed stain & 57.08 & 12.42 & 58.49 & 11.73 & -1.141 & $0.263 \mathrm{~ns}$ & 4.8 \\
\hline incisal edge & 59.51 & 12.02 & 59.57 & 12.00 & -0.043 & $0.965 \mathrm{~ns}$ & 5.2 \\
\hline gingival contour & 63.52 & 12.95 & 61.87 & 11.38 & 0.834 & $0.410 \mathrm{~ns}$ & 7.6 \\
\hline black triangle & 73.28 & 15.08 & 72.68 & 13.54 & 0.271 & $0.788 \mathrm{~ns}$ & 8.3 \\
\hline reference photograph & 60.94 & 13.48 & 60.02 & 11.17 & 0.467 & $0.643 \mathrm{~ns}$ & 7.5 \\
\hline
\end{tabular}

Table 2 - Mean and standard deviation (SD) values at T1 and T2, $\mathrm{t}$ test for paired samples and Dahlberg formula for assessment of systematic error and casual error for the measurements in the second evaluation.

\begin{tabular}{|c|c|c|c|c|c|c|c|}
\hline \multirow[t]{2}{*}{$\begin{array}{l}\text { Characteristics } \\
\text { (inclusion) }\end{array}$} & \multicolumn{2}{|c|}{$\mathbf{T}_{1}$} & \multicolumn{2}{|c|}{$\mathbf{T}_{2}$} & $\mathbf{t}$ & $\mathbf{p}$ & Dahlberg \\
\hline & Mean & SD & Mean & SD & & & \\
\hline yellowed stain & 64.32 & 14.82 & 65.37 & 12.22 & -0.490 & $0.627 \mathrm{~ns}$ & 8.2 \\
\hline incisal edge & 63.13 & 11.11 & 65.86 & 11.53 & -1.977 & $0.057 \mathrm{~ns}$ & 5.6 \\
\hline gingival contour & 59.80 & 13.13 & 62.53 & 12.10 & -1.710 & 0.097 ns & 6.4 \\
\hline black triangle & 52.37 & 11.04 & 54.74 & 9.97 & -1.826 & $0.078 \mathrm{~ns}$ & 5.2 \\
\hline reference photograph & 64.04 & 12.88 & 66.83 & 10.78 & -1.885 & $0.069 \mathrm{~ns}$ & 6.0 \\
\hline
\end{tabular}

Table 3 - Mean and standard deviation (SD) values for each assessed characteristic in the two evaluations.

\begin{tabular}{|c|c|c|c|c|c|}
\hline \multirow[t]{2}{*}{ Characteristics } & \multirow[t]{2}{*}{$\mathbf{N}$} & \multicolumn{2}{|c|}{ First evaluation (exclusion) } & \multicolumn{2}{|c|}{ Second evaluation (inclusion) } \\
\hline & & Mean & SD & Mean & SD \\
\hline yellowed stain & 60 & 57.78 & 12.00 & 64.84 & 13.48 \\
\hline incisal edge & 60 & 59.54 & 11.91 & 64.50 & 11.31 \\
\hline gingival contour & 60 & 62.70 & 12.12 & 61.16 & 12.59 \\
\hline black triangle & 60 & 72.98 & 14.21 & 53.56 & 10.50 \\
\hline reference photograph & 60 & 60.48 & 12.28 & 65.44 & 11.86 \\
\hline
\end{tabular}


measures related to the other characteristics, in both the first and second evaluation. The other comparisons did not yield any statistically significant results (Tables 4 and 5).

\section{DISCUSSION}

This study investigated the effect of certain dental characteristics on smile esthetics by evaluating whether they were perceptible for undergraduate Dentistry students using two evaluations: with inclusion and exclusion of details.

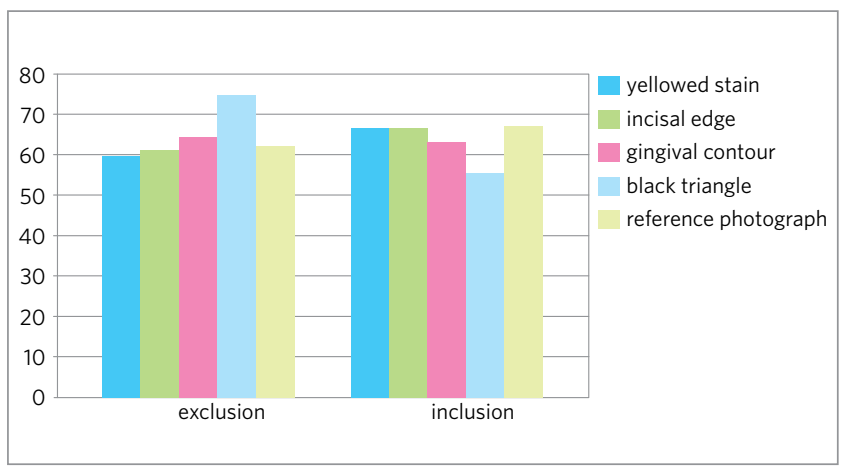

Figure 3 - Mean values for the assessed characteristics in the two evaluations: exclusion and inclusion of characteristics.
Intraexaminer tests showed that the results were coherent; the scores assigned were very similar and the values were very close (Tables 1 and 2).

In the first evaluation, the reference photograph, which had all the characteristics, might be expected to receive the lowest grade (Table 3), but that was not the case. A possible cause for this finding may be the order of photographs' projection, which was defined randomly. Another reason for this result may be the fact that the yellowed stain in tooth \#26, and the incisal edge's asymmetrical triangular shape of tooth \# 22 when compared with \#12,

Table 4 - Significance ( $p$ value) for the mean differences of comparisons between the assessed characteristics when they were excluded.

\begin{tabular}{|c|c|c|c|c|c|}
\hline & \multicolumn{5}{|c|}{ First evaluation (exclusion) - Significance } \\
\hline & yellowed stain & incisal edge & gingival contour & black triangle & reference photograph \\
\hline yellowed stain & - & 0.939 & 0.200 & $0.000^{\star}$ & 0.763 \\
\hline incisal edge & 0.939 & - & 0.642 & $0.000^{\star}$ & 0.994 \\
\hline gingival contour & 0.200 & 0.642 & - & $0.000^{*}$ & 0.869 \\
\hline black triangle & $0.000^{*}$ & $0.000^{*}$ & $0.000^{*}$ & - & $0.000^{\star}$ \\
\hline reference photograph & 0.763 & 0.994 & 0.869 & $0.000^{\star}$ & - \\
\hline
\end{tabular}

* = significant at the level of $5 \%$.

Table 5 - Significance ( $p$ value) for the mean differences of comparisons between the assessed characteristics when they were included.

\begin{tabular}{cccccc} 
& \multicolumn{4}{c}{ Second evaluation (inclusion) - Significance } \\
& yellowed stain & incisal edge & gingival contour & black triangle & reference photograph \\
yellowed stain & - & 1.000 & 0.447 & $0.000^{*}$ & 0.999 \\
incisal edge & 1.000 & - & 0.548 & $0.000^{*}$ & 0.993 \\
gingival contour & 0.447 & 0.548 & - & $0.05^{*}$ & -290 \\
black triangle & $0.000^{*}$ & $0.000^{*}$ & $0.000^{*}$ & $0.000^{*}$ & $0.000^{*}$ \\
reference photograph & 0.999 & 0.993 & 0.290 & - & - \\
\hline
\end{tabular}

* = significant at the level of $5 \%$. 
were mild characteristics and possibly not perceived by undergraduate students. These details could not be considered factors that compromise the perception of smile esthetics by this specific group of examiners.

In the second evaluation, the reference photograph, which was fully corrected, that is, displaying none of the characteristics under evaluation, received the highest score by the students and was considered the most esthetic smile (Table 3).

Among the characteristics defined for the evaluation of smile esthetics, the presence of a black triangular space between maxillary central incisors was the one most often perceived as having a negative effect on smile esthetics. The comparisons of the measures corresponding to this characteristic were statistically significant at the level of $5 \%$. All other comparisons did not reach statistic significance (Tables 4 and 5). These results were observed in both evaluations: in the first evaluation, in which the characteristics were excluded from the photographs; and in the second evaluation, when the characteristics were included in the photographs (Fig 3). The results of this study are in agreement with others that found that the interdental papilla may decrease the esthetic quality of the smile.,

The interdental papilla in present the interproximal space when the distance between the contact point and the bone crest level is not greater than $5 \mathrm{~mm}$; however, when this distance is greater than $7 \mathrm{~mm}$, the papilla is absent. ${ }^{15}$ Other factors may contribute to the absence of the interdental papilla and the consequent presence of a black triangular space: divergent roots in maxillary central incisors; altered dental crown shape; ${ }^{5}$ and distance between two adjacent teeth. Moreover, gingival papilla recession between central incisors is significantly associated with age, and may be a sign of ageing. ${ }^{\text {T }}$ Therefore, this result may be justified by a possible association with ageing, by the fact that the triangular space was black and located in the anterior region, between central incisors, which is the most visible portion of the smile.
The same reasoning that explains the role of location may apply to the little perception of the yellowed stain in the left maxillary first molar. If the stain were located in the anterior region, it might have been noticed. Moreover, the intensity of the stain color may also have affected results, in the present study it was pale and might have looked even paler during projection, which might have made it difficult for the students to perceive it.

The results for the triangular and asymmetric incisal edge anatomy of \# 22 when compared with \#12 suggest that they were mild characteristics, which might explain their little effect on the perception of smile esthetics.

Although the difference in gingiva height of tooth \# 12 in comparison with \#22 was apparently perceived by students, statistical analysis of those measures did not reveal statistically significant differences when compared to the grades given to the reference photographs.

Undergraduate students might not yet have received the necessary training to perceive the effect of certain tooth characteristics on smile esthetics. For this reason, future studies should enroll examiners with longer experience in Dentistry.

Training and years of experience in perceiving, measuring and defining the need to correct possible characteristics that affect the perception of smile esthetics are, therefore, factors that should receive greater attention in future studies.

\section{CONCLUSIONS}

The results of present study, given its methodological limitation, suggest that, although some tooth characteristics might affect the perception of smile esthetics, not all were promptly perceived by undergraduate students.

Among the characteristics under analysis, the black triangular space had the most unfavorable esthetic results. 


\section{REFERENCES}

1. Chang LC. The association between embrasure morphology and central papilla recession. J Clin Periodontol. 2007 May;34(5):432-6.

2. Houston WJ. The analysis of errors in orthodontic measurements. Am J Orthod. 1983 May;83(5):382-90.

3. Kerosuo $H$, Hausen $H$, Laine T, Shaw WC. The influence of incisal malocclusion on the social attractiveness of young adults in Finland. Eur J Orthod. 1995 Dec;17(6):505-12.

4. Kokich VG. Esthetics: the orthodontic-periodontic restorative connection. Semin Orthod. 1996 Mar;2(1):21-30.

5. Kokich VO Jr, Kiyak HA, Shapiro PA. Comparing the perception of dentists and lay people to altered dental esthetics. J Esthet Dent. 1999;11(6):311-24.

6. Martegani P, Silvestri M, Mascarello F, Scipioni T, Ghezzi C, Rota C, Cattaneo V. Morphometric study of the interproximal unit in the esthetic region to correlate anatomic variables affecting the aspect of soft tissue embrasure space. J Periodontol. 2007 Dec;78(12):2260-5.

7. Morley J, Eubank J. Macroesthetic elements of smile design. J Am Dent Assoc. 2001 Jan;132(1):39-45.

8. Peck S. Introdução. Secção II: Relevância da estética facial na Ortodontia. In: Sadowsky PL, editor. Atualidades em Ortodontia. São Paulo (SP): Premier; 1997. p. 250.
9. Pinheiro FHDSL, Beltrão RTS, Freitas MRD, Lauris JRP, Henriques JFC. Comparação da percepção e necessidade estética de tratamento ortodôntico entre pacientes e ortodontistas das cidades de Natal/RN e João Pessoa/PB. Rev Dental Press Ortodon Ortop Facial. 2005;10(2):54-61

10. Pinho S, Ciriaco C, Faber J, Lenza MA. Impact of dental asymmetries on the perception of smile esthetics. Am J Orthod Dentofacial Orthop. 2007 Dec;132(6):748-53.

11. Reis SAB, Abrão J, Capelozza Filho L, Claro, CAA. Análise Facial Subjetiva. Rev Dental Press Ortodon Ortop Facial. 2006 Set-Out;11(5):159-72.

12. Sabri R. The eight components of a balanced smile. J Clin Orthod. 2005 Mar;39(3):155-67; quiz 154.

13. Shaw WC, Rees G, Dawe M, Charles CR. The influence of dentofacial appearance on the social attractiveness of young adults. Am J Orthod. 1985 Jan;87(1):21-6.

14. Takei $\mathrm{H}$, Yamada $\mathrm{H}$, Hau T. Maxillary anterior esthetics. Preservation of the interdental papilla. Dent Clin North Am. 1989 Apr;33(2):263-73.

15. Tarnow DP, Magner AW, Fletcher P. The effect of the distance from the contact point to the crest of bone on the presence or absence of the interproximal dental papilla. J Periodontol. 1992 Dec;63(12):995-6. 